\title{
Ophthalmomyiasis Caused by Oestrus ovis
}

\author{
Neha Gautam ${ }^{1}$, Mandeep Tomar $^{2}$, Chaman Thakur ${ }^{1}$, Anil Kanga ${ }^{1}$ \\ ${ }^{1}$ Department of Microbiology, Dr YS Parmar Govt Medical College, Nahan, Sirmaur, Himachal Pradesh, India \\ ${ }^{2}$ Department of Ophthalmology, Dr YS Parmar Govt Medical College, Nahan, Sirmaur, Himachal Pradesh, India
}

\begin{abstract}
Ophthalmomyiasis externa refers to the involvement of external surface of eyes by the larvae of dipterous flies. We here describe case of external ophthalmomyiasis wherein larvae (five in number) were removed by using forceps under local anaesthesia and identified as larvae of Oestrus ovis. J Microbiol Infect Dis 2019; 9(4):161-163.
\end{abstract}

Keywords: Ophthalmomyiasis, Oestrus ovis, larvae

\section{INTRODUCTION}

Myiasis, the invasion of living and/or dead animal tissue by dipterous fly larvae is common in countries with poor hygiene and abundant flies. Ophthalmomyiasis occurs in about $5 \%$ of all cases of myiasis and can manifest in three forms; Ophthalmomyiasis externa where the larvae involve external surface of the eyes (lids, conjunctiva or lacrimal ducts), ophthalmomyiasis interna where larvae penetrate into the eyeball and orbital ophthalmomyiasis involving the orbit [1]. The latter two are known to cause serious damage including blindness. EOM caused by dipterous fly larvae has been reported from various parts of India [2-6]. Most of these cases have been due to Oestrus ovis, and a few (mostly of orbital disease) due to Chrysomia [5]. Here we report a case of an adult female presenting as ophthalmomyiasis externa.

\section{CASE}

A 26-year old female presented to the Ophthalmology department with complaints of pain, irritation, foreign body sensation and watering of the right eye for one day. She complained that something had entered into her right eye, when she was working in a field following which the symptoms started. The patient was not in close contact with animals like sheep, goats and cows. There was no significant medical history.

An ophthalmic examination revealed a visual acuity of $6 / 6$ in both the eyes. The cornea was clear and conjunctiva was congested, with profuse lacrimation in the right eye. The intraocular pressure was normal in both the eyes. The lacrimal sac was clinically patent. Slit lamp examination, revealed approximately $1 \mathrm{~mm}$ long translucent organisms with black heads, moving over the palpebral and bulbar conjunctiva in the right eye. Five larvae were removed by using a sterile plain fine forceps under topical $0.5 \%$ proparacaine and were sent to the Microbiology for identification. The other eye was also examined for larvae. No larvae were seen.

On microscopy, the larvae measured about $2 x$ $0.5 \mathrm{~mm}$ and were motile. They had characteristic dark brown oral hooks connected to the large internal cephalopharyngeal skeleton. Their body was divided into 11 segments, each being covered by numerous brown hooks. The eleventh segment was bilobed, each lobe having 12 hooklets. The larvae were thus identified as Oestrus ovis (sheep nasal botfly) (Figure 1). After the removal of the larvae, the patient was treated with topical moxifloxacin $0.5 \%$ with fluorometholone, artificial tears, anti-

Correspondence: Dr. Neha Gautam, Deparment of Microbiology, Dr YS Parmar Govt Medical College, Nahan, Sirmaur, Himachal Pradesh, India 
inflammatory drugs along with topical antibiotic ointment at bed time. The patient was instructed

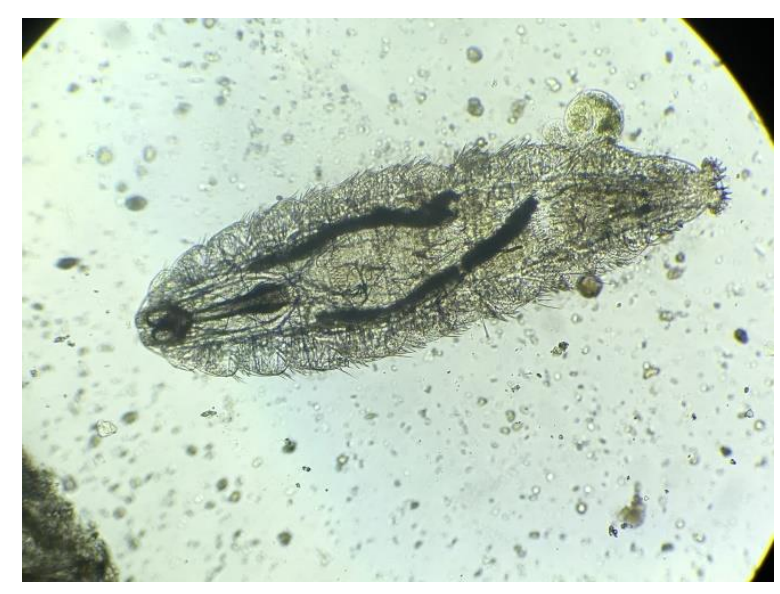

Figure 1. Larva of Oestrus ovis showing oral hooks and internal cephalopharingeal sekelet on (X 10).

\section{DISCUSSION}

Though the incidence of Ophthalmomyiasis is greater in areas where people are involved in sheep raising, Ophthalmomyiasis due to Oestrus ovis is worldwide in distribution [7-8] Bot flies (Oestridae or oestrids) are obligate parasites and sheep are the natural hosts [1]. Man is the accidental host. The fly swarms close to the eyes or nostrils and deposit larvae while still in flight. Shepherds are at greatest risk but poor living and hygiene conditions of patients may also contribute as a risk factor. Our patient did not have direct contact with sheep but belonged to a sheep raising area.

The patient of EOM presents with pain, itching, redness, and watering in the affected eyes, often accompanied by the sensation of a foreign body moving in the eye. Many patients report an insect striking them in the eye immediately prior to the onset of symptoms. The signs of EOM are eyelid edema, conjunctival edema, hemorrhages and chemosis. Therefore, the condition has to be differentiated from viral or allergic conjunctivitis. It may also mimic periorbital cellulitis if the disease involves the eyeball or orbit in rare cases [9]. In our patient, the disease was limited to conjunctiva as the patient approached the health facility within a day after the onset of symptoms and was diagnosed early. Similar case has been reported previously from our state almost a decade back [4]. It is to attend follow up examination.

startling that such infestation is emerging again in our area. This could be firstly; due the fact that the patients do not seek medical advice for this condition, as the disease usually a remains confined to conjunctiva and is self-limiting [10]. The larvae do not live beyond the first stage and die within ten days in humans. The other reasons could be misdiagnosis or underreporting of such cases.

The slit lamp examination under local anesthesia usually helps in clinching the diagnosis. The dark mouth claws and the active movements of their bodies against the conjunctiva help in the identification of these larvae. Since the larvae anchor to the tissue with the help of hooks therefore simple saline washing is not helpful. Manual removal of these larvae with forceps remains the ideal treatment. Double eversion of the eyelid is often necessary to find other maggots in the fornices.

Local anesthetics facilitate the removal of the larvae. Local antibiotics prevent secondary infection and topical steroids can be given to reduce the inflammation. A follow up examination is recommended to rule out the existence of additional larvae and prevent possible complications.

\section{ACKNOWLEDGMENTS}

Declaration of Conflicting Interests: The authors declare that they have no conflict of interest.

\section{Funding: None of declare.}

\section{REFERENCES}

1. Glasgow BJ. Ophthalmomyiasis. Chapter 108. In: Pepose JS, Holland GN, Wilhelmus KR, editors. Ocular Infection and Immunity. 1st ed. Mosby Publishers; St. Louis, Missouri, USA: 1996. P. 1505-1515.

2. Narayan S, Jayaprakash K. Incidence of ocular myiasis due to infection with the larva of Oestrus ovis (Oestridae diptera). Indian $\mathrm{J}$ Ophthalmol 1991; 39:176-8.

3. Mathai E, George JA, Lalitha MK, Raju R. Ophthalmomyiasis externa caused by Oestrus ovis - a case report from south India. Indian J Pathol Microbiol 1994; 37:205-7.

4. Thakur K, Singh G, Chauhan S, Sood A. Vidi, vini, vinci: External ophthalmomyiasis infection that occurred, and was diagnosed and treated in a 
single day: A rare case report. Oman $J$ Ophthalmol 2009; 2:130-132.

5. Singh I, Gathwala G, Yadav SP, Wig U. Ocular myiasis. Indain Pediatr 1994; 28:1524-1525.

6. Khurana S, Biswal M, Bhatti HS, Pandav SS, Gupta A, Chatterjee SS, et al. Ophthalmomyiasis: Three cases from North India. Indian J Med Microbiol 2010; 28:257-261.

7. Zumpt F. Ophthalmomyiasis in man, with special reference to the situation in Southern Africa. S Afr Med J 1963; 37:425-428.

8. Hoffmann BL, Goldsmid JM. Ophthalmomyiasis caused by Oestrus ovis L. (Diptera: Oestridae) in Rhodesia. S Afr Med J 1970; 44:644-645.

9. Cameron JA, Shoukrey NM, al-Garni AA. Conjunctival ophthalmomyiasis caused by the sheep nasal botfly (Oestrus ovis). Am J Ophthalmol 1991; 112:331-4

10. Lane RP, Crosskey RW. Medical insects and arachnids. London: Chapman and Hall; 1993. 